\title{
Oral health status of disabled children attending special schools of Dhaka city.
}

\author{
Dr.Md.Rakibul Hassan Khan ${ }^{1 *}$, Dr.Mottakin Ahmad², Dr.Md.Meftaul Islam³ ${ }^{3}$ Dr. Shaikh Ahmed ${ }^{4}$,
} Dr. Md. Rubayet Alam Prodhan ${ }^{5}$, Dr. Sharminakter ${ }^{6}$

\section{AFFILIATION:}

1. Dr.Md.Rakibul Hassan Khan, BDS,MPH (NIPSOM) Assistant Professor\& Head, Department of Dental Public Health, TMSS Medical College Dental Unit, Bogura.

2. Dr.Mottakin Ahmad, BDS, MPH (NIPSOM), Assistant Professor \& Head, Department of Paediatric Dentistry, TMSS Medical College Dental Unit, Bogura.

3. Dr.Md.Meftaul Islam ,BDS,DDS. Associate Professor \& Head, Department of Science of Dental Materials, TMSS Medical College Dental unit, Bogura.

4. Dr. Shaikh Ahmed BDS, FCPS (OMS), Assistant Professor, Department of Oral and Maxillofacial Surgery, TMSS Medical College Dental Unit, Bogura.

5. Dr. Md. Rubayet Alam Prodhan BDS, Lecturer, Department of Orthodontic, TMSS Medical College Dental Unit, Bogura.

6. Dr. Sharminakter, BDS, Lecturer, Department of Dental Public Health, TMSS Medical College Dental Unit, Bogura.

\section{Article info.}

Received: $1^{\text {st }}$ January, 2019

Accepted: $15^{\text {th }}$ March, 2019

Volume: 9, Issue-2 October, 2019

DOI:

https://doi.org/10.3329/updcj.v9i2.43737

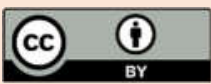

(c) Authors retain copyright and grant the journal right of first publication with the work simultaneously licensed under Creative Commons Attribution License CC - BY 4.0 that allows others to share the work with an acknowledgment of the work's authorship and initial publication in this journal.

https://creativecommons.org/licenses/by/4.0/

Publisher: Update Dental College, Dhaka, Bangladesh

Web: www.updatedentalcollege.edu.bd

E-mail: updcj@hotmail.com

\section{* Corresponding Author \\ Dr. MD. Rakibul Hassan Khan \\ BDS, MPH (NIPSOM)}

Assist. Professor \& Head, Dept. of Dental Public Health

TMSS Medical College Dental Unit, Thengamara, Bogra.

Mobile No: +8801718771724

E-mail: consultantrakib@gmail.com

\section{Citation}

Dr.Md.Rakibul Hassan Khan, Dr.Mottakin Ahmad, Dr.Md.Meftaul Islam, Dr. Shaikh Ahmed,Dr. Md. Rubayet Alam Prodhan, Dr. Sharmin akter, Oral health status of disabled children attending special schools of Dhaka city. Update Dental College Journal. 2019 October; 9(2):32-35 DOI: https://doi.org/10.3329/updcj.v9i2.43737

\begin{abstract}
Background: Children with disabilities and special needs present unique challenges for oral health professionals in the planning and carrying out of dental treatment. oral health care workers need to take cognizance of when preparing treatment plans for children with special needs. Children with disabilities are considered to be a high risk group for dental diseases specially dental caries and periodontal disease. High rates of dental caries, missing teeth, periodontal disease and malocclusion are all indicators of poor oral health of children with disabilities. Objectives:The aim of the study was to assess the oral health status of disabled children in special schools of Dhaka city. Study design: This was a cross sectional study. Study settings and period: The study was conducted in two elementary schools at mirpur area of Dhaka city in the period between of between february 2014 to January 2015.

Subjects: 200 disabled children with the age range from 6 to 14 belonging to six different disability groups were examined. Participants were grouped according to their type of disability autistic children, Down syndrome, Cerebralpulsy, mute and deaf, blind and physical disability.Methods: Data was collected by using semi structured quationnaire and checklist.Datawere analyzed by statistical package of social science(SPSS- 20). Results: According to disability the participants autistic $44 \%$, cerebral pulsy $37 \%$, down syndrome $35 \%$, blind $28 \%$, deaf and mute $30 \%$ and physical disability $30 \%$. The average number of decayed tooth was found $6.89 \%$. Mean DMFT value was 4.75 . Average number of missing tooth was $1.89 \%$.Prevalence of dental caries highest $71 \%$ in autistic children then other cetagory of disabilty .Oral hygiene practice of the respondent found very poor.76\% children brush teeth in the morning and once in a day. $49 \%$ respondent use toothpick to clean food from in between teeth. $37 \%$ of the respondent never visited to dentist. $34.5 \%$ respondents had normal gingiva, $49 \%$ had mild gingivitis and $16.5 \%$ had marked gingivitis. Highest numbers of trauma cases were recorded in visually impaired group. $98.7 \%$ children required some form of dental treatment. Conclusion: Oral health status of children with disabilities was poor and it is important to concentrate on a preventive approach and provide proper dental education to parents of disabled childrens. More attention should be paid to the oral hygiene practice of disabled children
\end{abstract}

\section{KEY WORDS:}

Caries, Disabled children, Oral Health, Hygiene

\section{INTRODUCTION:}

Disability is a universal element in the human condition to which no one is immune. Unrecognized as a problem for development, the condition of being disabled is at the bottom of the development agenda. This low priority can be explained in public choice theoretic terms by the political weakness of disabled persons and by the high perceived economic costs and low perceived political benefits of a state response to problems which are administratively anomalous and transactions-costly ${ }^{1}$. Such a calculus operates more powerfully on the comprehension of the issues and welfare agendas of the least developed countries like Bangladesh than that of developed ones. The comprehension on disability, throughout the history, has rested on make-belief ideas. The direct result of these stereo-typed imaging and consequential action by the society and policy on the persons with disabilities has been 
their neglect ${ }^{2,6}$. This neglect bars persons with disabilities from normal economic, social and political activities in their families, communities, essential services and education, etc In Bangladesh, there have been only a few systemic interventions to raise awareness of persons with disabilities at the community level. They are usually excluded from existing governmental and non-governmental development programmes ${ }^{4}$. The number of employed persons with disabilities is assumed to be less than $1 \%$.Such neglect is a top as national data on disability is very scarce and is far from reflecting the reality. There have been no attempts to conduct regular national disability prevalence survey 3 by the national statistical agency, Bangladesh Bureau of Statistics . Action AidBangladesh and Social Assistance and Rehabilitation for the Physically Vulnerable put the percent of person with disability at $8.8 \%$ of the total population. Bangladesh ProtibandiKalayanSamiti records $7.8 \%$, while in another survey Action Aid Bangladesh (1996) records $14.04 \%$ people suffered from a form of impairment ${ }^{4,5}$. On the other hand, the Government of Bangladesh (GOB) surveys in 1982, 1986 and 1998 estimated a national prevalence rate of disability at $0.64 \%, 0.5 \%$ and $1.60 \%$ respectively. The WHO"s global estimate predicts approximately $10 \%$ of all people have a disability of one kind or another ${ }^{4,5}$. Bangladesh with some sources quoting a higher disability rate in rural Bangladesh. Oral health is a vital component of overall health, which contributes to each individual"s well-being and quality of life by positively affecting physical and mental wellbeing, appearance, and interpersonal relations ${ }^{3}$. Oral health is an important aspect of health for all children, and is more important for children with special health needs. People with disabilities deserve the same opportunities for oral health and hygiene as those who are healthy. Unfortunately, oral health care is of the greatest underserved health needs of the disabled people. Inadequate dental care or poor dental public health measurements may have negative influence on their oral health status. Dental caries is also the major cause of tooth loss in individuals with physical and mental disabilities. Several studies have noted that disabled subjects have higher levels of caries, lower levels of care and a much higher proportion of untreated lesions but receive less treatment than the normal population. Logical studies reported that children with disabilities tended to have poorer oral hygiene and a greater prevalence and increased severity of periodontal disease than their normal counterparts ${ }^{12}$. Around $10 \%$ of the world"s population, or 650 million people, live with a disability. This figure is increasing through population growth, medical advances and the ageing process. According to the UN Development Programme around $80 \%$ of people with disabilities live in developing countries ${ }^{5,7}$. There are a myriad medical, social, psychological, oral and dental considerations that oral health care workers need to take cognizance of when preparing treatment plans for children with special needs. If all these factors are fully integrated into the treatment plan, the resulting care and management will provide the best chance of helping the individual with special needs to achieve and maintain a lifetime of good oral health ${ }^{7,9}$.

\section{MATERIALS AND METHODS:}

This descriptive type of cross sectional study was conducted between the period of February 2014 to January 2015 in two elementary school of Dhaka city. After obtaining the ethical clearance from the institutional ethical committee. 200 disabled children with the age range from 6 to 14 belonging to six different disability groups were examined.students were selected purposively as study sample. Participants were grouped according to their age 6-8,9-11,12-14 and to their type of disability autistic children, Down syndrome, Cerebral pulsy, mute and deaf, blind and physical disability. Data were collected by using structured quationnaire and checklist was used to find out the oral health indices DMFT (Decay, missing, filling, treatment need index) and CPITN (Community periodontal index). Data collected through face-to-face interview of gardians of the students. Oralexamination of the students done after taking

verbal consent of the class teachers and parents. Data were collected on the basis of knowledge about dental problem, maintenance of oral hygienic tools, knowledge of prevention of dental disease and ,oral hygienic index, periodontal index, plaque index, gingival index. Materials used for oral examination were-dental caries probe, dental mirror, cotton, antiseptic solution. The students' dental examinations were carried out with torch light on normal chair. Pointed end of the caries probe was gently pressed over the black marks if any on the tooth surface to identify carious teeth.Tip of the periodontal probe was introduced into the selected gingival margin to score the gingival condition. The data were checked before leaving the interview area and necessary correction were made at the spot. Statistical Analysis: SPSSsoftware package (version 20) was used to analyze the data. Descriptive statistics were used for all variables. Values were expressed as percentage.

\section{RESULTS:}

Among 200 disabled children $57 \%$ were male and $43 \%$ were female. According to age group $6-8=40.50 \%, 9-11=35.50 \%, 12-$ $14=24 \%$. According to disability autistic $44 \%$, cerebral pulsy $37 \%$, down syndrome $35 \%$, blind $28 \%$, deaf and mute $30 \%$ and physical disability $30 \%$. The average number of decayed tooth was found 6.89. Mean DMFT value was 4.75. Average number of missing tooth was $1.89 \%$.Prevalence of dental caries in autistic children $70 \%$,cerebral pulsy62\%,Down syndrome $55 \%$,blind $31 \%$,deaf $22 \%$,physical disability $27 \%$.Oral hygiene practice of the respondent found very poor.76\% children brush teeth in the morning and once in a day. $49 \%$ respondent use toothpick to clean food from in between teeth.59.5\% parents don't know about using fluoride containing toothpaste. $37 \%$ of the respondent never visited to dentist. $16.5 \%$ respondents had normal gingiva, $46 \%$ had moderate gingivitis and $16 \%$ had severe gingivitis. Highest numbers of trauma cases were 
recorded in visually impaired group. $93.7 \%$ children required some form of dental treatment.

Figure 1: Distribution showing caries prevalence according to disability of participants.

\section{Caries prevelence}

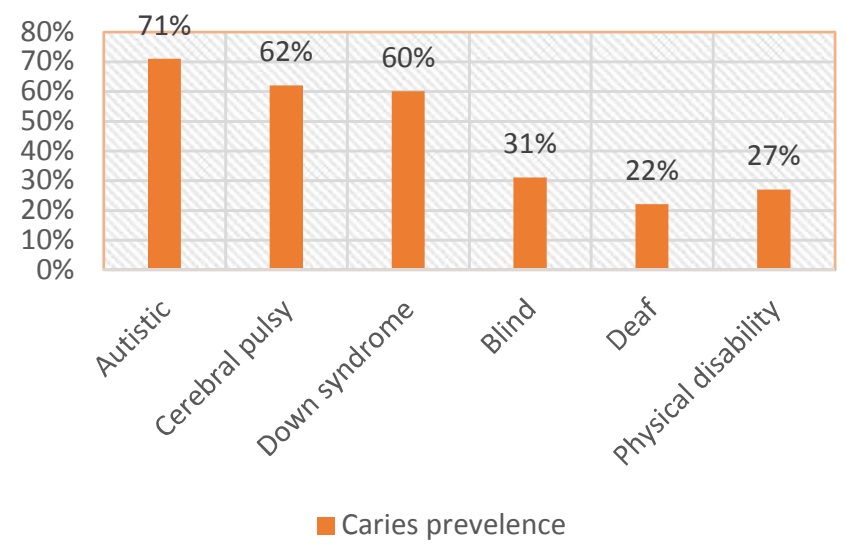

The figure 1 reflects higher rate of caries prevalence among all groups of participants. Caries prevalence higher in autistic children $71 \%$, cerebral palsy $62 \%$,Down syndrome $60 \%$, blind $31 \%$,deaf $22 \%$ and physical disability $27 \%$.

Table 1: Distribution showing caries prevalence in primary dentition and permanent dentition by disability type.

\begin{tabular}{|c|c|c|}
\hline Disability type & $\begin{array}{l}\text { Primary } \quad \text { Dentition } \\
\text { caries prevalence(\%) }\end{array}$ & $\begin{array}{l}\text { Permanent Dentition } \\
\text { caries prevalence }(\%)\end{array}$ \\
\hline Autism & $73.8(26.2)$ & $60(40)$ \\
\hline Cerebral pulsy & $62.2(25.8)$ & $65.8(10.2)$ \\
\hline Down syndrome & $54.5(44.5)$ & $58.9(25)$ \\
\hline Blind & $31(23.5)$ & $82(11.5)$ \\
\hline Deaf & $37(24.5)$ & $62(32)$ \\
\hline Physical disability & 27 (18.1) & $45(22)$ \\
\hline
\end{tabular}

Table 1 reflects caires prevalence in primary and permanent dentition among all the disability.where higher caries prevalence in both primary and permanent dention found in autistic children ,cerebralpulsy and down syndrome then other cetagory of disability.

Table 2: Distribution showing mean value of DMFT by disability type:

\begin{tabular}{llll}
\hline Disability type & $\begin{array}{l}\text { Mean (SD) } \\
\text { of DMF(T) }\end{array}$ & Median(IQR) & $\begin{array}{l}\text { P-value(KruskaWallis } \\
\text { test) }\end{array}$ \\
\hline Autism & $4.9 \pm 3.3$ & $22.0(4.0)$ & \\
\hline Down syndrome & $3.9 \pm 5$ & $24.0(6.0)$ & \\
\hline Cerebral pulsy & $4.6 \pm 8.1$ & $3.0(8.0)$ & $<0.001$ \\
\hline Blind & $3.7 \pm 3.9$ & $4.0(4.0)$ & \\
\hline Deaf & $2.9 \pm 4.2$ & $3.0(5.0)$ & \\
\hline $\begin{array}{l}\text { Physical } \\
\text { disability }\end{array}$ & $3.7 \pm 3.9$ & $4.0(4.0)$ & \\
\hline Total (N-200) & $4.75 \pm 2$ & $3.0(4.0)$ & \\
\hline
\end{tabular}

Table 2 reflects mean DMFT for total population is 4.75 . Autistic children has higher DMFT index (4.9 \pm 3.3$)$ and lowest in deaf and mute children (2.9 \pm 4.2$)$
Figure 2 : Distribution of periodontal status among all disability

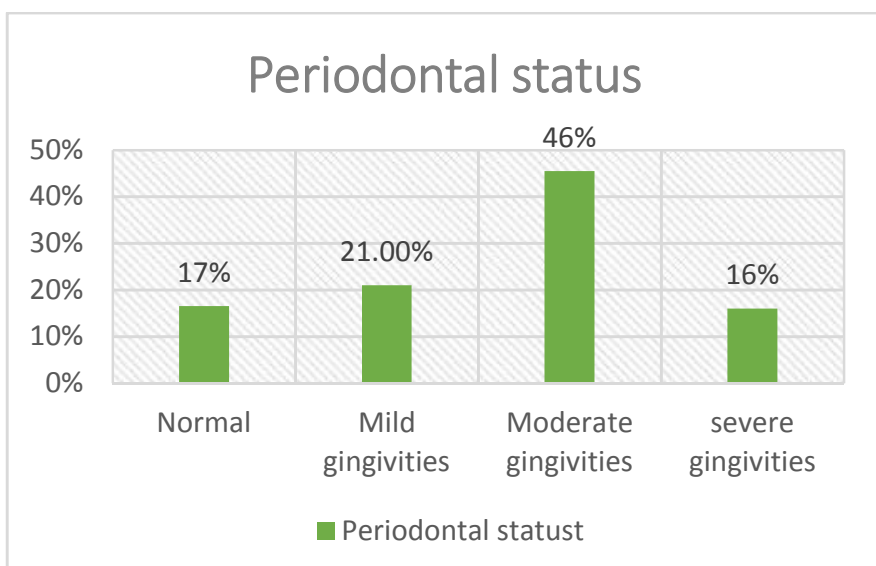

Figure 2 reflects periodontal status among all disabled child. where moderate gingivitis found $46 \%$,severe gingivities $16 \%$,mild gingivities $21 \%$ and normal $17 \%$.

\section{DISCUSSION:}

Oral diseases are one of the common health problems among individuals with disabilities. The prevalence and severity of oral disease among this group are higher when compared to the general population. ${ }^{6}$ As a result of low physical abilities with subsequent difficulties in maintaining oral hygiene, these individuals have poor oral cleanliness. ${ }^{11,12}$ This study was conducted to assess the oral health status of specially challenged children in two elementary school of Dhaka city. Oral hygiene of majority of the study participants was compromised due to the presence of calculus and/or bleeding gums with no significant difference among the disability types. Many studies have reported similar findings, and this has been attributed to improper bushing technique and inadequate knowledge of oral hygiene practices despite the high prevalence of parental attention. ${ }^{11,21,22}$ Similar findings are reported in studies conducted in Turkey by Altunet al. ${ }^{22}$ among 136 disabled individuals and Gizaniet $a .^{21}$ in Belgium among 12-year-old disabled children which showed poor oral hygiene in $31.8 \%$ of children, with no significant differences found among disability types. Several other studies 12,14 have also found poor results for periodontal health and oral cleanliness among children with disabilities. These results may be due to low physical abilities, which could cause difficulties in tooth brushing among disabled children.

DMFT index was used to measure the dental caries levels among the study population. The overall DMFT and dft levels were higher in females compared to males. These findings are similar to those found in many other studies conducted in Saudi Arabia, North Korea, Israel, and Canary islands..$^{22}$ Overall DMFT levels in our study population were around 4.75 for deciduous dentition and 3.89 in permanent dentition. Similarly, higher levels of caries were reported in other studies. ${ }^{24, G i z a n i e t ~ a l . ~}{ }^{21}$ reported a mean DMFT value of 4.75 . 
Important factor to be considered here is that improvement of the oral health depends on the awareness of their families of the importance of oral hygiene habits. In our study, we found higher proportion of decayed teeth and very few filled teeth which points to the fact that the dental care for these children was nearly nonexistent. We found a significant difference in caries burden in children of different disabilities. Children with autistic,cerebralpulsy and Down's syndrome had significantly higher caries burden. Similar findings have been reported by Gardens et al. ${ }^{2}$ Furthermore, it was found in our study that the filled teeth and missing teeth were present among the study participants. This can be attributed to the fact that majority of the children were noninstitutional and had access to dental services. The treatment needs reflect the high need for restorative and rehabilitative world ..$^{2,12}$

\section{CONCLUSION:}

A high proportion of treatment needs found in this study reflect the barriers to access and utilize oral health care among these children. Furthermore, a high cost of dental treatment may further discourage the children and their caregivers from getting the treatment. Concerned authorities should take necessary steps in improving the oral health of these children and take steps to provide the caretakers the monetary support needed to achieve optimum health of children. As dentist, we should emphasize on health education and periodic recall and monitoring among these individuals.

\section{REFERENCES:}

1. Fereday J, Oster C, Darbyshire P. Partnership in practice: What parents of a disabled child want from a generic health professional in Australia. Health Soc Care Community 2010;18:624-32. https://doi.org/10.1111/i.1365-2524.2010.00935.x PMid:20561077

2. Gardens SJ, Krishna M, Vellappally S, Alzoman H, Halawany HS, Abraham NB, et al. Oral health survey of 6-12-year-old children with disabilities attending special schools in Chennai, India. Int J Paediatr Dent 2014;24:424-33. https://doi.org/10.1111/ipd.12088

PMid:24372860

3. Demyttenaere K, Bruffaerts R, Posada-Villa J, Gasquet I, Kovess V, Lepine JP, et al. Prevalence, severity, and unmet need for treatment of mental disorders in the World Health Organization world mental health surveys. JAMA 2004;291:2581-90.

\section{https://doi.org/10.1001/jama.291.21.2581}

\section{PMid:15173149}

4. Bangladesh leadership in Autism is exemplary.( Apr 6,2011).'Bangladesh leadership in Autism is exemplary'says Autism Speaks Co- founders at the NYSE Opening Bell..Available:http://www.un.int/wcm/webdav/sit/Bangladesh/ shared /files/ Autism-NYSE-2.pdf.

5. Purohit BM, Singh A. Oral health status of 12 -year-old children with disabilities and controls in Southern India. WHO South East Asia J Public Health 2012;1:330-8.

https://doi.org/10.4103/2224-3151.207029 PMid:28615559

6. M MRahman Autism spectrum Disorder. J Bangladesh CollPhyssurg 2010;28:143-144. https://doi.org/10.3329/jbcps.v28i3.6506
7. Nelson LP, Getzin A, Graham D, Zhou J, Wagle EM, McQuiston J, et al. Unmet dental needs and barriers to care for children with significant special health care needs. Pediatr Dent 2011;33:29-36.

8. Evans DJ, Greening S, French AD. A study of the dental health of children and young adults attending special schools in South Glamorgan. Int J Paediatr Dent 1991;1:17-24.

https://doi.org/10.1111/j.1365-263X.1991.tb00316.x PMid:1834168

9. James AE. Risk, Vulnerability, and Resilience; an overview. The Invulnerable Child, New York: Guilford Press; 1987. p. 3-48.

10. Klingberg $\mathrm{G}$, Hallberg $\mathrm{U}$. Oral health-Not a priority issue a grounded theory analysis of barriers for young patients with disabilities to receive oral health care on the same premise as others. Eur J Oral Sci 2012;120:232-8.

https://doi.org/10.1111/i.1600-0722.2012.00961.x PMid:22607340

11. Ivancić Jokić N, Majstorović M, Bakarcić D, Katalinić A, Szirovicza L. Dental caries in disabled children. CollAntropol 2007;31:321-4.

12. lida $\mathrm{H}$, Lewis $\mathrm{CW}$. Utility of a summative scale based on the Children with Special Health Care Needs (CSHCN) screener to identify CSHCN with special dental care needs. Matern Child Health J 2012;16:1164-72. https://doi.org/10.1007/s10995-011-0894-6 PMid:21997705

13. Shaw L, Maclaurin ET, Foster TD. Dental study of handicapped children attending special schools in Birmingham, UK. Community Dent Oral Epidemiol 1986;14:24-7.

https://doi.org/10.1111/j.1600-0528.1986.tb01488.x PMid:2937607

14. Hennequin M, Faulks D, Roux D. Accuracy of estimation of dental treatment need in special care patients. J Dent 2000;28:131-6. https://doi.org/10.1016/S0300-5712(99)00052-4

15. Shapira J, Efrat J, Berkey D, Mann J. Dental health profile of a population with mental retardation in Israel. Spec Care Dentist 1998;18:149-55. https://doi.org/10.1111/j.1754-4505.1998.tb01137.x PMid:10218062

16. Dunning JM. Principles of Dental Public Health. Cambridge: Harvard University Press; 1986.

17. Stabholz A, Mann J, Sela M, Schurr D, Steinberg D, Shapira J, et al. Caries experience, periodontal treatment needs, salivary $\mathrm{pH}$, and Streptococcus mutans counts in a preadolescent down syndrome population. Spec Care Dentist 1991;11:203-8. https://doi.org/10.1111/j.1754-4505.1991.tb01732.x PMid:1839870

18. Casamassimo PS, Seale NS, Ruehs K. General dentists' perceptions of educational and treatment issues affecting access to care for children with special health care needs. J Dent Educ 2004;68:23-8.

19. Forsberg H, Quick-Nilsson I, Gustavson KH, Jagell S. Dental health and dental care in severely mentally retarded children. Swed Dent J 1985;9:15-28.

20. Jain M, Bharadwaj SP, Kaira LS, Bharadwaj SP, Chopra D, Prabu D, et al. Oral health status and treatment need among institutionalised hearingimpaired and blind children and young adults in Udaipur, India. A comparative study. Oral Health Dent Manag 2013;12:41-9.

21. Gizani S, Declerck D, Vinckier F, Martens L, Marks L, Goffin G, et al. Oral health condition of 12-year-old handicapped children in Flanders (Belgium). Community Dent Oral Epidemiol 1997;25:352-7. https://doi.org/10.1111/j.1600-0528.1997.tb00954.x PMid:9355771

22. Altun C, Guven G, Akgun OM, Akkurt MD, Basak F, Akbulut E, et al. Oral health status of disabled individuals attending special schools. Eur J Dent 2010;4:361-6.

https://doi.org/10.1055/s-0039-1697854PMid:20922154 PMCid:PMC2948746

Website: https://www.banglajol.info/index.php/UpDCJ 